\title{
IN GERIATRIC INDIVIDUALS - COMMUNITY ACQUIRED PNEUMONIA
}

\author{
Irfan Ahamed H. B', Aniruddha Udupa K2, Mohammed Ismail'3, Syed Aman Jagirdar ${ }^{4}$, Naveen Sagar H. M5
}

${ }^{1}$ Assistant Professor, Department of Medicine, Al-Ameen Medical College, Bijapur.

${ }^{2}$ Assistant Professor, Department of Pulmonology, Subbaiah Medical College, Shimoga.

${ }^{3}$ Postgraduate, Department of Medicine, Al-Ameen Medical College, Bijapur.

${ }^{4}$ Postgraduate, Department of Medicine, Al-Ameen Medical College, Bijapur.

5Postgraduate, Department of Medicine, Al-Ameen Medical College, Bijapur.

\begin{tabular}{l}
\hline ABSTRACT \\
BACKGROUND \\
Community acquired pneumonia in the elderly has increased as a consequence of an overall increase in elderly population. CAP in \\
elderly has a different clinical presentation and higher mortality than in other age groups. The present study was conducted to study \\
the clinical, radiological and bacteriological profile of CAP in elderly.
\end{tabular}

\section{MATERIALS AND METHODS}

Prospective study was conducted at Al-Ameen Medical College Hospital and district hospital, Bijapur. A total of 50 patients of community acquired pneumonia of age above 65 years admitted in the hospital were included in the study. A detailed history, clinical examination, laboratory investigations, chest x-ray and sputum examination was carried out on all patients. Data was analysed for clinical presentations, aetiology, outcome and the prognostic factors.

\section{RESULTS}

Age group of patients varied from 66 - 88 years. Patients presented with both typical and atypical symptoms; 8 (16\%) patients presented with altered sensorium. Most patients had associated co-morbid conditions. Smoking and COPD were the most common predisposing factors. Causative organism was isolated by sputum culture in only $18(36 \%)$ patients. Streptococcus pneumonia was most common, isolated in $8(16 \%)$ patients. Other organisms isolated were Klebsiella pneumonia in $3(6 \%)$ patients, pseudomonas in $2(4 \%)$, haemophilus influenza in $2(4 \%)$, Staphylococcus aureus in $1(2 \%)$ and E. coli in $1(2 \%)$ patients. Mortality was seen in 8 (16\%) patients. The following prognostic factors showed to have statistically significant association with mortality; altered sensorium, presence of associated diseases, temperature $>38^{\circ} \mathrm{C}$ or $<35^{\circ} \mathrm{C}$, pulse rate $>100 / \mathrm{min}$, systolic blood pressure $<90 \mathrm{mmHg}$, leucocytosis $>11,000$ cells/cumm, leukopenia $<4000$ cells/cumm, raised urea $>40 \mathrm{mg} / \mathrm{dL}$, hyponatraemia, ARDS and septic shock.

\section{CONCLUSION}

According to our study elderly patients with CAP may present with both typical and atypical clinical presentations, have associated co-morbid conditions and higher mortality. Causative organisms can be identified in only few cases. Hence, there is a need for clinical suspicion, early diagnosis and appropriate treatment.

\section{KEYWORDS}

Elderly, Geriatric, Community Acquired Pneumonia.

HOW TO CITE THIS ARTICLE: Ahamed IHB, Udupa AK, Ismail M, et al. In geriatric individuals - community acquired pneumonia. J. Evolution Med. Dent. Sci. 2016;5(89):6639-6644, DOI: 10.14260/Jemds/2016/1502

\section{BACKGROUND}

Pneumonia 'the captain of men of death,' 'the friend of the aged,' allowing them a merciful relief from those cold gradations of decay, that make the last state of all so distressing as described by William Osler, is one of the most common infectious disease encountered in the clinical practice.[1]

Pneumonia is the sixth leading cause of death in the United States.[2] About 600,000 persons with pneumonia are hospitalised each year and there are 64.

Financial or Other, Competing Interest: None.

Submission 18-10-2016, Peer Review 31-10-2016,

Acceptance 02-11-2016, Published 07-11-2016.

Corresponding Author:

Dr. Irfan Ahamed H. B,

S/o. K. B. Basheer Ahamed,

$1^{\text {st }}$ Stage, $2^{\text {nd }}$ Cross,

Door \#15, Iqbal Manzil

Dr. Ram Manohar Lohiya Nagar,

Shimoga- 577201, Karnataka.

E-mail:dr.irfan28@gmail.com

DOI: $10.14260 /$ jemds/2016/1502

(c) $(7)$
Million days of restricted activity due to this illness. In developed countries, almost one-half of total hospitalisation for pneumonia occur in patients over 65 years and pneumonia is a leading cause of death in this age group. ${ }^{[3]}$ Managing pneumonia in an elderly patient requires an appreciation of many aspects of geriatric medicine including the demographics of our aging population.[4]

Most patients who require hospitalisation for the treatment of Community Acquired Pneumonia (CAP) are elderly. The elderly have impaired function of many organs by virtue of the aging process and as a result of comorbidity. ${ }^{[5]}$ There are structural and functional alterations in old age, which impair the host's defense against pulmonary infection. $[6,7]$

Elderly patients hospitalised because of CAP constitute a special population since they commonly have underlying illnesses, prior neurologic disturbances, nutritional and immunologic deficits. Delay in diagnosis and treatment may contribute to the higher observed death rate in the elderly population with CAP. ${ }^{8}$ Hence, the following study was undertaken to study the clinical, radiological and 
bacteriological profile of community acquired pneumonia in elderly.

\section{MATERIALS AND METHODS}

The present study was conducted at Al-Ameen Medical College Hospital and District Hospital, Bijapur (affiliated to Al-Ameen Medical College) between December 2008 and June 2010. This study is a prospective study carried out on 50 cases of community acquired pneumonia of patients aged $>65$ years. Prior to the study, the protocol was approved by the Institutional Ethical Committee and all patients gave their informed consent to participate.

\section{Inclusion Criteria}

a) Age $>65$ years.

b) Clinical symptoms like fever, cough with or without expectoration, pleuritic chest pain, dyspnoea and altered sensorium.

c) Clinical signs like tachypnoea, reduced chest movements, dull percussion note, bronchial breath sounds, increased vocal fremitus and vocal resonance and crepitations.

d) Radiological evidence of pneumonia without any clinical evidence of pneumonia will also be included.

\section{Exclusion Criteria}

a) Hospital acquired pneumonia, that is patient hospitalised in the previous 14 days.

b) HIV positive status.

c) Tuberculosis.

d) Lung malignancies.

Patient demographic features were recorded according to a standard questionnaire. A detailed clinical history was taken. History for comorbid illness and habits like smoking and alcoholism were taken. Comorbid illnesses were defined as the presence of co-existing cardiac failure, ischaemic heart disease, chronic lung disease (COPD), chronic liver disease (cirrhosis of liver), chronic kidney disease (Diabetic nephropathy), malignancies (multiple myeloma), neurological diseases (old h/o strokes) and diabetes mellitus.

\section{Statistical Analysis}

The data was analysed by mean + SD (Standard deviation), Percentage and Chi-square test ( $P$ value $<0.05$ was considered significant).

\section{RESULTS}

The present study was conducted at Al-Ameen Medical College Hospital and District Hospital, Bijapur (affiliated to Al-Ameen Medical College) between December 2008 and June 2010. This study is a prospective study carried out on 50 cases of hospitalised community acquired pneumonia patients aged $>$ 65 years. A detailed history was taken, clinical parameters on admission were noted, routine investigations, chest $\mathrm{x}$-ray and sputum examination were carried out on all patients. The results and observations of the study are as follows.

\section{Age Distribution}

In this study, the age group of patients varied from 66 to 88 years. Mean age was $72.22+6.14$ years. Majority of patients were in the age group 65 - 74 years.

\section{Sex Distribution}

Out of 50 patients, 35 (70\%) were males and 15 (30\%) were females.

\section{Predisposing Conditions}

Among the predisposing conditions, COPD was the most common noted in $24(48 \%)$ patients. Other predisposing conditions noted were diabetes mellitus in $14(28 \%)$ patients, congestive cardiac failure in $8(16 \%)$, neurologic diseases in 4 (8\%) patients, renal diseases in $3(6 \%)$ patients, chronic liver disease in $2(4 \%)$ patients and malignancy in $1(2 \%)$ patients. Among habits, smoking was most common noted in 32 (74\%) patients followed by alcoholism in $8(16 \%)$ patients.

\section{Symptomatology}

In this study, patients presented with both typical and atypical symptoms. Among the typical respiratory symptoms cough was present in 37 (74\%) patients, expectoration in 32 (64\%) patients, 23 had mucopurulent sputum and 9 patients had mucoid sputum, fever in $28(56 \%)$ patients, dyspnoea in 11 (22\%), pleuritic chest pain in $10(20 \%)$ patients. Among the atypical symptoms, altered sensorium was present in 8 (16\%) patients and gastrointestinal symptoms of anorexia, nausea, vomiting or diarrhoea in $4(8 \%)$ patients.

\section{Findings on General Physical Examination}

General physical examination of the patient showed pallor in $13(26 \%)$ patients, icterus in $6(12 \%)$ patients, cyanosis in 4 (8\%) patients, clubbing in $2(4 \%)$ and pedal oedema in $4(8 \%)$ patients.

\section{Vital Signs}

In this study raised temperature $>38^{\circ} \mathrm{C}$ was noted in $34(68 \%)$ patients, in 18 patients it was $38.9^{\circ} \mathrm{C}-39.9^{\circ} \mathrm{C}$ and 14 patients had $39.9^{\circ} \mathrm{C}-40^{\circ} \mathrm{C}$. Tachypnoea defined by respiratory rate $>$ $24 /$ min was noted in $42(84 \%)$ patients (25 had respiratory rate of $24-26 / \mathrm{min}$ and 17 patients had respiratory rate of 27 - 30/min), tachycardia defined as pulse rate $>100 /$ min was noted in $35(70 \%)$ patients ( 28 patients had pulse rate in range of $100-120 / \mathrm{min}$ and 7 patients had pulse rate of 120 . $130 / \mathrm{min}$ ). Hypotension defined as systolic blood pressure < $90 \mathrm{mmHg}$ was noted in $8(16 \%)$ patients (6 patients had SBP of $60-80 \mathrm{mmHg}$ and SBP was not recordable in 2 patients and hypothermia defined as temperature $<35^{\circ} \mathrm{C}$ was noted in 1 (2\%) patients $\left(34.6^{\circ} \mathrm{C}\right)$.

\section{Findings on Respiratory System Examination}

In this study, crepitation was the most common respiratory system examination findings, which was noted in 47 (94\%) patients. Other findings were reduced chest movements, impaired note on percussion, bronchial breathing, increased vocal fremitus and vocal resonance and pleural rub.

\section{Laboratory Characteristics}

Leukocytosis defined as total leukocyte count $>11,000 /$ cum was the most common, noted in 42 (84\%) patients. Leukopenia defined as total leukocyte count $<4,000 /$ cumm was noted in $4(8 \%)$ patients. Anaemia defined as $\mathrm{Hb}<11$ $\mathrm{gm} / \mathrm{dL}$ was noted in $16(32 \%)$ patients. ESR $>20 \mathrm{~mm}$ at 1 hour was noted in $38(76 \%)$ patients. Blood urea $>40 \mathrm{mg} / \mathrm{dL}$ was noted in $20(40 \%)$ patients. Serum creatinine $>1.4 \mathrm{mg} / \mathrm{dL}$ was noted in $8(16 \%)$ patients. Raised serum bilirubin $>1.2 \mathrm{mg} / \mathrm{dL}$ was noted in $6(12 \%)$, raised liver enzymes was noted in 8 (16\%) patients. Hypoalbuminaemia defined as serum albumin $<3.5 \mathrm{mg} / \mathrm{dL}$ was noted in $14(28 \%)$ patients. Hyponatraemia defined by serum sodium $<130 \mathrm{mEq} / \mathrm{L}$ was noted in $14(28 \%)$ and hypokalaemia was noted in $2(4 \%)$ patients. 


\section{Results of Sputum Gram Staining}

Adequate sputum sample showing bacteriological positivity could be obtained in only 26 (54\%) patients. Of these 16 (32\%) were gram positive cocci, $6(12 \%)$ were gram negative bacilli and $4(8 \%)$ were mixed.

\section{Results of Sputum Culture}

In this study, positive sputum culture was obtained in only 18 patients (32\%). Streptococcus pneumonia was the most common organism isolated obtained in $8(16 \%)$ patients followed by Klebsiella pneumonia in $3(6 \%)$ patients, pseudomonas in 2 (4\%), haemophilus influenza in $2(4 \%)$, Staphylococcus aureus in $1(2 \%)$ and E. coli in $1(2 \%)$ patients. Sputum gram staining and culture demonstrated correlation in 18 of 26 patients (with both gram staining and culture positivity and 8 patients had sterile cultures).

\section{Radiological Findings}

In this study lobar pneumonia was the most common radiological finding which was noted in 39 (78\%) patients, of which 26 patients had mid-to-lower zone consolidation, 8 patients had whole lung consolidation, 2 patients had upper zone consolidation and 3 had bilateral pneumonia. Out of 39 patients with lobar pneumonia, the distribution was 24 to the right lung, 12 to left lung and 3 bilateral.

\section{Complications}

The most common complication noted was septic shock in 8 (16\%) patients followed by pleural effusion in 6 (12\%) patients. The other complications noted were congestive cardiac failure, ARDS, lung abscess and emphysema.

\section{Mortality}

In this study, out of 50 patients $42(84 \%)$ patients improved and $8(16 \%)$ patients had mortality.

\begin{tabular}{|c|c|c|}
\hline Sex & Our Study & Riquemele et al \\
\hline Male & $70 \%$ & $67 \%$ \\
\hline Female & $30 \%$ & $33 \%$ \\
\hline Table 1. Sex Distribution in Study Conducted by us \& \\
Riquemele et al
\end{tabular}

\begin{tabular}{|c|c|c|c|c|}
\hline $\begin{array}{c}\text { Predisposing } \\
\text { Conditions }\end{array}$ & \multicolumn{2}{|c|}{ Our Study } & \multicolumn{2}{|c|}{$\begin{array}{c}\text { Antoni Torres } \\
\text { et al }\end{array}$} \\
\hline Smoking & 32 & $(74 \%)$ & 62 & $(62 \%)$ \\
\hline Alcoholism & 8 & $(6 \%)$ & 22 & $(22 \%)$ \\
\hline COPD & 24 & $(48 \%)$ & 30 & $(30 \%)$ \\
\hline Diabetes mellitus & 14 & $(24 \%)$ & \multicolumn{2}{|c|}{$1(17 \%)$} \\
\hline $\begin{array}{c}\text { Congestive cardiac } \\
\text { failure }\end{array}$ & \multicolumn{2}{|c|}{$8(16 \%)$} & 28 & $(28 \%)$ \\
\hline Neurologic diseases & 4 & $(8 \%)$ & 5 & $(5 \%)$ \\
\hline Renal diseases & 3 & $(6 \%)$ & 4 & $(4 \%)$ \\
\hline $\begin{array}{l}\text { Chronic liver } \\
\text { diseases }\end{array}$ & 2 & $(4 \%)$ & 4 & $(4 \%)$ \\
\hline Malignancy & 1 & $(2 \%)$ & 5 & $(5 \%)$ \\
\hline \multicolumn{5}{|c|}{$\begin{array}{c}\text { Table 2. Predisposing Factors Seen in Our Study and } \\
\text { Another Study Conducted by Antoni Torres et al is As } \\
\text { Follows }\end{array}$} \\
\hline
\end{tabular}

\begin{tabular}{|c|c|c|c|}
\hline $\begin{array}{c}\text { Presenting } \\
\text { Symptoms }\end{array}$ & $\begin{array}{c}\text { Our } \\
\text { Study }\end{array}$ & $\begin{array}{c}\text { Antoni } \\
\text { Torres } \\
\text { et al }\end{array}$ & $\begin{array}{c}\text { Kobashi } \\
\text { et al }\end{array}$ \\
\hline Cough & $\begin{array}{c}37 \\
(74 \%)\end{array}$ & $407(81 \%)$ & $52(62 \%)$ \\
\hline Expectoration & $\begin{array}{c}32 \\
(64 \%)\end{array}$ & $331(66 \%)$ & $47(56 \%)$ \\
\hline Fever & $\begin{array}{c}28 \\
(56 \%)\end{array}$ & $380(76 \%)$ & $47(56 \%)$ \\
\hline Dyspnoea & $\begin{array}{c}11 \\
(22 \%)\end{array}$ & $351(70 \%)$ & $16(19 \%)$ \\
\hline Pleuritic chest pain & $\begin{array}{c}10 \\
(20 \%)\end{array}$ & $218(43 \%)$ & $12(14 \%)$ \\
\hline Altered sensorium & $\begin{array}{c}8 \\
(16 \%)\end{array}$ & $130(26 \%)$ & $7(8 \%)$ \\
\hline $\begin{array}{c}\text { Gastrointestinal } \\
\text { symptoms }\end{array}$ & $4(8 \%)$ & $36(8 \%)$ & $7(8 \%)$ \\
\hline
\end{tabular}

Table 3. Clinical Presentation according to Our Study as well as Studies Conducted by Antoni Torres et al and Kobashi et al

\begin{tabular}{|c|c|c|}
\hline Vital Signs & $\begin{array}{c}\text { Present } \\
\text { Study }\end{array}$ & Kobashi et al \\
\hline Temperature $>38^{\circ} \mathrm{C}$ & $34(68 \%)$ & $47(56 \%)$ \\
\hline Tachypnoea $>24 / \mathrm{min}$ & $42(84 \%)$ & $59(70 \%)$ \\
\hline Tachycardia $>100 / \mathrm{min}$ & $35(70 \%)$ & $58(69 \%)$ \\
\hline $\begin{array}{c}\text { Hypotension }<90 \\
\text { mmHg }\end{array}$ & $8(16 \%)$ & $15(18 \%)$ \\
\hline Temperature $<35^{\circ} \mathrm{C}$ & $1(2 \%)$ & $1(1 \%)$ \\
\hline $\begin{array}{c}\text { Table 4. Vital Signs Noted in Our Study as well as in } \\
\text { Study Conducted by Kobashi et al }\end{array}$ \\
\hline
\end{tabular}

\begin{tabular}{|c|c|c|}
\hline Radiological Findings & $\begin{array}{c}\text { Our } \\
\text { Study }\end{array}$ & $\begin{array}{c}\text { Antoni Torres } \\
\text { et al }\end{array}$ \\
\hline Lobar pneumonia & $39(78 \%)$ & $367(82 \%)$ \\
\hline Bronchopneumonia & $9(18 \%)$ & $62(12 \%)$ \\
\hline Interstitial pneumonia & $2(4 \%)$ & $18(4 \%)$ \\
\hline Pleural effusion & $6(12 \%)$ & $60(11 \%)$ \\
\hline Cavitation & $2(4 \%)$ & $9(2 \%)$ \\
\hline Table 5. Radiological Findings in Our Study and Study \\
by Antoni Torres et al
\end{tabular}

\section{DISCUSSION}

Community Acquired Pneumonia (CAP) is a frequent cause of hospital admission and mortality in elderly patients worldwide. The clinical presentation, aetiology and outcome of community acquired pneumonia in elderly differs from that of other population. In the present study, 50 patients of community acquired pneumonia $>65$ years of age were included. The results of the study which has been presented previously is discussed below.

\section{Age}

Pneumonia is common in the extremes of age. In this study, the age group of patients presenting with community acquired pneumonia ranged from 66 to 88 years. Of these patients 32 (64\%) were aged 65 - 74 years, 14 (28\%) were aged 75 - 84 years and $4(8 \%)$ were aged $>85$ years.

In a study conducted by Meehan et al, 14,069 Medicare patients age $>65$ years who required hospitalisation for CAP were studied. They noted that $30.3 \%$ were aged $65-74$ years, $41.8 \%$ were aged $75-84$ years and $27.8 \%$ were aged $>85$ years.[9]

In another study by Torres et al, the mean age of elderly 
patients presenting with community acquired pneumonia was $78 \pm 8$ years (mean \pm SD). ${ }^{10}$ These differences may be due to differences in the rate of hospitalisation and access to health care of the elderly in the different populations studied.

\section{Sex Distribution}

In this study, males 35 (70\%) were affected more than females $15(30 \%)$. This sex distribution is similar to study conducted by Riquemele et al, where $67 \%$ were males and $33 \%$ were females. This may be attributed to increased rates of alcoholism and smoking in males and also due to the increased association of comorbid conditions like COPD, congestive cardiac failure and others in males. This is shown in Table 1.

\section{Predisposing Conditions}

The presence of chronic co-morbidity in most of the CAP patients in our study is compatible with the contention that an important risk factor for pneumonia in elderly people is the prevalence of other illnesses. ${ }^{[8]}$ This is shown in Table 2.

Kobashi et al studied 83 patients with elderly pneumonia. Thirty-eight patients $(45 \%)$ had a history of respiratory disease with Chronic Obstructive Pulmonary Disease (COPD) being most common (16 cases). Sixty-two patients (74\%) had a history of non-respiratory disease, most commonly cerebrovascular disease (16 patients). Fifty patients were current smoker (60\%) and 15 drank alcohol (16\%) regularly.[11]

Smoking was the most important risk factor $(72 \%)$ in our study. The increased risk of pneumonia in smokers is due to alteration in respiratory flora, mechanical clearance and cellular defenses. In a population-based case-control study, Nuorti et al found that cigarette smoking was the strongest independent risk factor for invasive pneumococcal disease.[10] In our study, COPD was most common associated comorbid condition (48\%). Increased incidence and mortality of pneumonia has been described in COPD patients. This is explained due to defective mucociliary clearance, mucous plugging, airway collapse, respiratory muscle fatigue and the effect of medications used.[12]

\section{Presenting Complaints}

Elderly patient may present with typical as well as atypical symptoms. Atypical symptoms are commonly described in elderly than in younger patients. Clinical presentation according to our study as well as studies conducted by Antoni Torres et al and Kobashi et al is shown in Table 3.

Harper and Newton found that the classical constellation of CAP in the elderly of cough, fever and dyspnoea was absent in $56 \%$ of patients.[13]

\section{General Physical Examination Findings}

In this study general physical examination of the patient showed pallor in $8(16 \%)$ patients which may be secondary to infection, associated comorbid conditions and malnutrition. Icterus was observed in $6(12 \%)$ patients. Central cyanosis observed in 4 (8\%) patients. Central cyanosis is explained due to shunting of blood through consolidated lung. Vital signs noted in our study as well as in study conducted by Kobashi et al is shown in Table 4.

In our study tachypnoea was the most common sign in 42 (84\%) patients followed by tachycardia 35 (70\%) patients. Fever the most frequently noted symptom of infection occurs less frequently in elderly. Poor febrile response was correlated to decrease release of IL-1 in elderly patients.[14]

\section{Findings of Respiratory System Examination}

Among the respiratory signs noted in our study crepitations was the most frequent finding noted in most of the patients 47 (94\%). In a study by Zalcain et al, crepitations was the most common respiratory finding noted in $79 \%$ of patients.

\section{Laboratory Data}

Among the laboratory investigations in our study leukocytosis was the most consistent finding noted in 42 (84\%) patients, whereas leukopenia was seen in $4(8 \%)$ patients and was associated with poor prognosis. In study by Torres et al, seventy-six (76\%) patients had a leukocyte count > $10.000 / \mathrm{mm}^{3}$. Elevated white blood cell counts in elderly people may be caused by the increased rate of pneumococcal infection in old age.

In our study raised blood urea was noted in 20 (40\%) patients, raised bilirubin in $6(12 \%)$ and raised liver enzymes in $8(16 \%)$ was noted. The hepatic impairment and the impaired renal function was more severe in the elderly age group compared to the younger groups in various studies. This may suggest a more severe systemic infection in this age group.[15]

In our study, serum albumin level was low in 14 (28\%) patients. Serum albumin level is commonly cited as a marker of nutritional status and it has been correlated independently with a higher case-fatality rate among persons with CAP.[16]

\section{Sputum Microscopy and Culture}

In this study, bacteriological positivity on gram staining of sputum was seen in $26(52 \%)$ of patients. Cultures were positive in only $18(32 \%)$ patients. Streptococcus pneumonia was the most common aetiological agent isolated, $8(16 \%)$ patients followed by gram negative bacilli like Klebsiella pneumonia $3(6 \%)$, pseudomonas aeruginosa $2(4 \%)$, E. coli 1 (2\%), haemophilus influenza $2(4 \%)$ and Staphylococcus aureus 1 (2\%) patient. This is almost similar to study conducted by Antony Torres et al, where sputum analysis was performed in $403(80 \%)$ cases and of these $186(46 \%)$ were of good quality and $71(38 \%)$ showed positive results, bacteriological diagnosis was achieved in 11 of 30 cases (37\%) with 13 microorganisms (five S. pneumoniae, two C. pneumoniae, one L. pneumophila, one P. aeruginosa, one Klebsiella pneumoniae, one Escherichia coli, one Staphylococcus aureus, one Streptococcus viridians.

Woodhead et al reviewed 11 studies that reported on the aetiology of pneumonia in the elderly and compared them to 3 studies of pneumonia in younger populations. The proportion of cases due to $\mathrm{H}$. influenzae, S. aureus and gram negative bacilli was higher among the elderly and the proportion due to Legionella another atypical pathogens was higher among the younger patients.[17]

Colonisation of the oropharyngeal mucosa with aerobic gram negative Bacilli like Escherichia coli, Klebsiella species, Proteus species, Enterobacter species and Pseudomonas aeruginosa increases with increasing age, predisposing to increased incidence of gram negative bacilli in aged.[18]

In various studies in Western counties undertaken to investigate the causes of community acquired pneumonia in the elderly, the distribution of causative pathogens appeared 
to differ from that in younger adults, S. pneumoniae was the most common causing about $50 \%$ of infections, respiratory viruses, H. influenza gram negative bacilli, C. pneumoniae and L. pneumophila were others commonly noted.[19]

The cause of CAP is often difficult to establish. The most effective methods are often invasive and cannot always be justified and serological diagnosis is too late to be of any therapeutic use. Despite the progress made in the diagnosis of pneumonia, it takes a few days to identify the causative microorganism in the blood or sputum samples and the aetiology of half of all patients with CAP remains uncertain. In addition to the clinical, laboratory and radiological findings in order to initiate antibiotic treatment empirically. The relative frequency of aetiological agents varies among different geographical areas.

\section{Radiological Presentation}

The radiological data in our study showed a predominance of lobar pneumonia in $39(78 \%)$ patients followed by bronchopneumonia in 9 (18\%) patients. Radiological data of our study compared with that due to Antoni Torres et al is shown in Table 5.

\section{Mortality}

In this study, $8(16 \%)$ patients had mortality. Mortality rates for elderly patients hospitalised with CAP in previous reports range from 6 to $40 \%$. Kaplan et al reported a mortality of $11 \%$ in elderly patients with community acquired pneumonia.[20]

\section{Prognostic Factors}

In our study, the following prognostic factors showed to have statistically significant association with mortality; altered sensorium, presence of associated diseases, temperature > $38^{\circ} \mathrm{C}$ or $<35^{\circ} \mathrm{C}$, Pulse rate $>100 / \mathrm{min}$, systolic blood pressure $<90 \mathrm{mmHg}$, leukocytosis > 11,000 cells/cumm, leukopenia < 4000 cells/cumm, raised urea $>40 \mathrm{mg} / \mathrm{dL}$, hyponatraemia, ARDS and septic shock.

Conte et al developed a prognostic rule for elderly patients admitted with CAP. They found five predictors of bad prognosis as follows: presence of comorbidity, abnormal vital signs axillary temperature $>38^{\circ} \mathrm{C}$, cardiac frequency $>110$ beats/min and systolic arterial pressure $<90 \mathrm{mmHg}$, age $>85$ yrs., alteration in mental state and plasma creatinine $>1.5$ $\mathrm{mg} / \mathrm{dL} .{ }^{[21]}$

\section{CONCLUSION}

Community acquired pneumonia in elderly patients is a common and serious problem encountered in clinical practice. Elderly patients with community acquired pneumonia have different clinical presentation and higher mortality. Elderly patients may present with atypical symptoms like altered sensorium and gastrointestinal symptoms other than the typical respiratory symptoms of pneumonia. They may not have all the classical signs of consolidation and may present with only a few signs like tachypnoea, tachycardia and crepitations. The atypical presentations may lead to delay in diagnosis and initiation of treatment and may be responsible for higher observed mortality in elderly patients with pneumonia.
Aetiological agents cannot be identified in many cases because of difficulty in collecting sputum in elderly patients, lower yield of culture and various atypical and difficult to isolate causative organisms. Hence, the need for an empirical therapy covering both typical and atypical organisms.

The following prognostic factors showed to have statistically significant association with mortality; altered sensorium, presence of associated diseases, temperature $>$ $38^{\circ} \mathrm{C}$ or $<35^{\circ} \mathrm{C}$, Pulse rate $>100 / \mathrm{min}$, systolic blood pressure $<90 \mathrm{mmHg}$, leukocytosis > 11,000 cells/cumm, leukopenia < 4000 cells/cumm, raised urea $>40 \mathrm{mg} / \mathrm{dL}$, hyponatraemia, ARDS and septic shock. Prospective studies on larger number of patients are required to substantiate these findings.

\section{REFERENCES}

1. Berk SL. Bacterial pneumonia in the elderly: the observations of Sir William Osler in retrospect. J Am Geriatr Soc 1984;32(9):683-5.

2. Dixon RE. Economic costs of respiratory tract infections in the United States. Am J Med 1985;78(6B):45-51.

3. National Centre for Health Statistics. National hospital discharge survey: annual summary 1990. Vital Health Statistics 1992;13:1-225.

4. Ochoa GO, Vila CA, Cintade D, et al. The burden of community acquired pneumonia in the elderly: the Spanish EVAN-65 study. BMC Public Health 2008;8:222.

5. Medina-Walpole AM, Katz PR. Nursing home-acquired pneumonia. J Am Geriatr Soc 1999;47(8):1005-15.

6. Cunha BA, Gingrich D, Rosenbaum GS. Pneumonia syndromes: a clinical approach in the elderly. Geriatrics 1990;45(10):49-55.

7. Fein AM, Feinsilver SH, Niedennan MS. Atypical manifestation of pneumonia in the elderly. Clin Chest Med 1991;12(2):319-36.

8. Venkatesan P, Gladman J, Macfarlane JT, et al. A hospital study of community acquired pneumonia in the elderly. Thorax 1990;45(4):254-8.

9. Granton JT, Grossman RF. Community-acquired pneumonia in the elderly patient. Clinical features, epidemiology, and treatment. Clin Chest Med 1993;14(3):537-53.

10. Riquelme $\mathrm{R}$, Torres $\mathrm{A}$, el-Ebiary $\mathrm{M}$, et al. Communityacquired pneumonia in the elderly. Clinical and nutritional aspects. Am J Respir Crit Care Med 1997;156(6):1908-14.

11. Meehan TP, Fine MJ, Krumholz HM, et al. Quality of care, process and outcomes in elderly patients with pneumonia. JAMA 1997;278(23):2080-4.

12. Fein AM, Niederman MS. Severe pneumonia in the elderly. Clin Ger Med 1994;10(1):121-43.

13. Nuorti JP, Butler JC, Farley MM, et al. Cigarette smoking and invasive pneumococcal disease. Active bacterial core surveillance team. N Engl J Med 2000;342(10):681-9.

14. Torres A, Dorca J, Zalacain R, et al. Community-acquired pneumonia in chronic obstructive pulmonary disease: a Spanish multicenter study. Am J Respir Crit Care Med 1996;154(5):1456-61.

15. Kauffmann CA, Jones PG, Kluger MJ. Fever and malnutrition: endogenous pyrogen, IL-1 in malnourished elderly patients. Am J Clin Nutr 1986;44(4):449-52.

16. Valenti WM, Trudell RG, Bentley DW. Factors predisposing to oropharyngeal colonization with gram negative bacilli in the aged. N Engl J Med 1978;298(20):1108-11. 
17. Niederman MS, Fein AM. Community-acquired pneumonia in the elderly. In: Niederman MS. (eds) Respiratory infections in the Elderly. Raven Press, New York, 1991: 44-72.

18. Ishida $\mathrm{T}$, Hashimoto $\mathrm{T}$, Arita $\mathrm{M}$, et al. Etiology of community-acquired pneumonia in hospitalized patients: a-3-year prospective study in Japan. Chest 1998;114(6): 1588-93.

19. Lieberman D, Schalaeffer F, Boldur I, et al. Multiple pathogens in adult patients admitted with community acquired pneumonia: a one year prospective study of 346 consecutive patients. Thorax 1996;51(2):179-84.
20. Kaplan V, Angus DC, Griffin MF, et al. Hospitalized community-acquired pneumonia in the elderly: age and sex-related patterns of care and outcome in the United States. Am J Respir Crit Care Med 2002;165(6):766-72.

21. Conte HA, Chen YT, Mehal W, et al. A prognostic rule for elderly patients admitted with community acquired pneumonia. Am J Med 1999;106(1):20-8. 